\title{
ASSOCIATION BETWEEN HLA ANTIGENS AND PROGRESSION OF HIV INFECTION IN GREEK HAEMOPHILIACS
}

\author{
CHR. PAPASTERIADES $\stackrel{\ddagger}{\star}$, J. ECONOMIDOU $\stackrel{\ddagger}{\ddagger}$ H. PAPPAS $\stackrel{\ddagger}{\ddagger}$, K. PSARRA $\stackrel{\ddagger}{\ddagger}$, V. KAPSIMALI \\ K. KARAFOULIDOU ${ }^{\dagger}$, T. MANDALAKI ${ }^{\dagger}$, G. PAPAEVANGELOU $\$$. \\ $¥$ Dept. of Immunology and Histocompatibility, Evangelismos Hospital, Athens, Greece. \\ ${ }^{\dagger}$ Haemophilia Centre, Laikon General Hospital, Athens, Greece. \\ $\S$ AIDS Reference Centre, Athens School of Hygiene, Athens, Greece.
}

\section{SUMMARY}

The frequencies of HLA antigens in 33 HIV seronegative and in 88 HIV seropositive haemophiliacs, who have been followed for at least 6 years since seroconversion or first HIV positive test, were evaluated in relation to disease susceptibility and disease progression. A high frequency of HLA-A2 and -DR2 antigens and a low frequency of HLA-A9 were found to characterize HIV seropositive patients $(\mathrm{p}<0.05)$. Progressors to symptomatic CDC stage IV had a higher frequency of HLA-A9 $(\mathrm{p}<0.01)$ and DR3. Rapid decline of CD4+ T cells in these patients was associated with HLA-A9, -DR1 and DR3. Our data suggest that HLA antigens may contribute to susceptibility to HIV infection and disease progression in Greek haemophiliacs.

KEY WORDS HLA antigens Haemophilia CD4+ T lymphocytes CDC staging

\section{INTRODUCTION}

HLA molecules play an important role in the susceptibility and progression of certain autoimmune and infectious diseases. Several published studies provide evidence that various MHC factors may be associated with susceptibility or resistance to HIV infection and progression to AIDS (Pollack et al., 1983; Raffoux et al., 1987; Mann et al., 1988; Steel et al., 1988; Jeannet et al., 1989; Fabio et al., 1990; Moreno et al., 1991 and Cameron et al., 1991). However, the reported HLA associations are conflicting. This may be due to heterogeneity in the genetic background and mode of HIV transmission in the groups studied as well as in the duration of HIV infection. Cohorts of haemophiliacs are particularly suitable for such a study because of the close medical follow up of this group of patients and the known date of seroconversion in most cases.

In a previous study of 60 unrelated Greek haemophiliacs, we were unable to detect any association between HLA-A, B and DR antigens and susceptibility or resistance to HIV infection (Papasteriades et al., 1986). Having now data on a larger group of patients who are known to be HIV infected for more than six years, we have further extended the study investigating whether the HLA antigens are a predisposing factor for the development of AIDS.

\footnotetext{
* Requests for reprints to: Dr. Chr. Papasteriades, Dept. of Immunology and Histocompatibility, Evangelismos Hospital, Athens 106 76, Greece.
} 


\section{SUBJECTS AND METHODS}

\section{Subjects}

The study included 88 HIV seropositive haemophiliacs of Greek origin, aged 9 to 65 years ( 83 with haemophilia A, 4 with haemophilia B and 1 with von Willebrand disease), who have been followed for six to ten years (median $\geq 7$ years) since their first HIV positive test. Twenty one of them had known date of seroconversion.

The patients were divided in two groups according to CDC clinical stage. Forty four of them were still in stage II or III (slow progressors) and 44 in stage IV. The median age of the two groups was 29 (9-58) years and 33 (11-67) years respectively. The patients were also grouped according to the number of CD4+ T lymphocytes at the time of evaluation. Forty six patients had more than 200 cells $/ \mu 1$ (median 342 cells/ $\mu$ l, range $207-871$ cells/ $\mu 1$ ), and 43 patients had less than 200 cells $/ \mu 1$ (median 96 cells $/ \mu 1$, range $4-196$ cells $/ \mu 1$ ). Thirty four of the $88 \mathrm{HIV}+$ haemophiliacs in this study received AZT when the CD4+ T cell number declined below the level of 200 cells $/ \mu 1$, irrespective of the CDC stage of HIV infection (mostly asymtomatic cases). At the same time of analysis three of them showed an increase in their CD4+ T cell counts ( $>200$ cells/ $\mu \mathrm{l})$ following drug administration. Therefore, in the analysis the pre-treatment number of CD4+ T cell counts was used. During the follow up period, 14 patients died, 9 of them due to progression of AIDS and 5 from other causes.

A group of 33 HIV seronegative haemophiliacs and a panel of 433 healthy unrelated individuals, all of Greek origin, were also typed for HLA antigens during the same period of time.

\section{Methods}

The standard two stage complement-dependent microlymphocytotoxicity technique was performed for the HLA-A, B typing using 144 selected antisera. HLA-DR typing was carried out on B lymphocytes (after removing T lymphocytes by rosetting with AET treated sheep erythrocytes) with 72 antisera. T lymphocyte phenotyping was carried out during follow up at 4 or 6 months intervals with an EPICS-C flow cytometer (Coulter). Absolute numbers of CD4+ T cells were estimated. Statistical analysis was performed by using $\chi^{2}$ test.

\section{RESULTS}

The distribution of HLA-A, B antigen frequencies showed no statistically significant differences between haemophilia patients and controls. Of the seven HLA-DR antigens (DR1-DR7) studied, HLA-DR5 was present with a higher frequency in the patients than in the controls $\left(62.9 \%\right.$ vs $36.4 \%, \chi^{2}=22.036, p<0.001$, R.R:2.96). However, there was no difference in the frequency of DR5 between HIV seropositive and seronegative haemophiliacs $(60.2 \%$ vs $69.7 \%)$. HIV seronegative haemophiliacs showed a higher frequency of HLA-A9 in comparison to HIV seropositive patients $(51.5 \%$ vs $29.5 \%$, $\left.\chi^{2}=5.056, \mathrm{p}<0.05, \mathrm{R} . \mathrm{R}: 2.53\right)$ and a lower frequency of HLA-A2 and -DR2 (27.3\% vs $47.7 \%, \chi^{2}=4.118, \mathrm{p}<0.05$, R.R:0.41 and $24.2 \%$ vs $46.9 \%, \chi^{2}=5.068, \mathrm{p}<0.05$, R.R:0.36 respectively). (Table 1 ).

The frequencies of certain HLA antigens in haemophiliacs grouped according to the CDC stage of HIV infection at the end of the follow up period are shown in Table 2. 
Patients who progressed to stage IV, in comparison to those who remained in stages II and III, showed a higher frequency of HLA-A9 $\left(43.1 \%\right.$ vs $15.9 \%, \chi^{2}=7.861, \mathrm{p}<0.01$, R.R:4.01) and -DR3 (25\% vs $10.2 \%, \chi^{2}=3.035,0.05>$ p $<0.1$ R.R:2.91).

Table 3 presents the distribution of the same antigens in the patients grouped according to CD $4+T$ cell counts. (Group I with CD4+ T cell counts $\geq 200$ cells $/ \mu 1$ and group II with CD4+ T cell counts $<200$ cells $/ \mu$ l). HLA-A9 and HLA -DR 1 were observed with higher frequency in group II than in group I patients $\left(36 \%\right.$ vs $19.4 \%, \chi^{2}=2.86$, R.R: 2.33 and $27.0 \%$ vs $12.1 \%, \chi^{2}=3.619$, R.R: 2.63 respectively), but these differences did not reach statistically significant levels.

\section{DISCUSSION}

Studies of HLA antigens in HIV infected subjects have provided some evidence that HLA molecules may play a role in the susceptibility to HIV infection and in disease progression (Scorza et al., 1986; Steel et al., 1988; Jeannet et al., 1989; Fabio et al., 1990; Hershow et al., 1991; Moreno et al., 1991; Letenneur et al., 1991; and Mann et al., 1991), and that several HLA alleles may be associated with certain manifestations of the disease (Pollack et al., 1983; Enlow et al., 1983; Raffoux et al., 1987 and Itestu et al., 1989).

In this work, we have observed an increased frequency of HLA-A2 in HIV seropositive compared to seronegative haemophiliacs, a finding which is in agreement with that reported in a study by Fabio et al. (1990) also in haemophiliacs. Taking into account the role of the HLA - class 1 molecules in antigen presentation to the T cytotoxic cells and the observation that a specific epitope of HIV 1 gp 120 is restricted by the HLAA2 antigen in HIV infected subjects (Walker and Plata, 1990), a further investigation of the role of HLA-A 2 and probably of its variants in the specific cytotoxic response against the virus will be of interest. We also observed an increased frequency of HLA-DR2 in HIV seropositive haemophiliacs. This may represent a host genetic factor contributing to susceptibility or may reflect a chance distribution since there is no previous report of this association. Our observation of negative association of HIV infection with HLA-A9 has not been confirmed by others, who have observed such an association with HLA-B62 (Hershow et al., 1991), -BW52, -DR4 (Fabio et al., 1990) and-B44 (Scorza et al., 1986).

HIV infection has a long incubation period, and the progression of the disease may be influenced by environmental or other cofactors and by genetic factors. In order to evaluate the contribution of genetic background to the variability of disease progression, the informative group must be homogeneous in terms of group at risk for HIV infection, with known date of seroconversion and long follow up. In our study only part of the cohort $(25 \%)$ had known date of seroconversion. However, the patients have been followed up for at least 6 years since seroconversion or first HIV positive test, and thus the group with slow progression of HIV infection can be compared to those who progressed to CDC stage IV. Increased frequency of HLA-A9 and -DR3 was found to characterize our haemophiliacs with rapid progression. Association of HLA-DR3 as part of the haplotype HLA-A 1B8DR3 with less favourable clinical course was found by Steel et al., (1988) in haemophiliacs infected by a single batch of factor VIII contaminated with HIV. HLA-DR3 and-DQW2 were found to be associated with a high risk for developing symptomatic HIV infection in Italian haemophiliacs (Fabio et al., 1990). Other antigens such as HLA-B35 (Scorza et al., 1986), -DR5 (Mengoli et al., 1988) and -DR1 in combination with HLA-B35 (Mallal et al., 1990), which have been reported to influence 
Table 1. Comparison of HLA antigen frequencies between haemophiliacs and controls, and between HIV seropositive and seronegative.

\begin{tabular}{|c|c|c|c|c|c|c|}
\hline & $\begin{array}{l}\text { Controls } \\
(\mathrm{N}=433)\end{array}$ & $\begin{array}{l}\text { All pts } \\
(\mathrm{N}=121)\end{array}$ & & $\begin{array}{l}\text { HIV- } \\
(\mathrm{N}=33)\end{array}$ & $\begin{array}{l}\text { HIV+ } \\
(\mathrm{N}=88)\end{array}$ & \\
\hline HLA* & $\%$ & $\%$ & $\mathrm{P}$ & $\%$ & $\%$ & $\mathrm{P}$ \\
\hline Al & 24.0 & 23.1 & n.s & 18.2 & 25.0 & n.s \\
\hline $\mathrm{A} 2$ & 53.1 & 42.1 & n.s & 27.3 & 47.7 & $<0.05$ \\
\hline A9 & 33.0 & 35.5 & n.s & 51.5 & 29.5 & $<0.05$ \\
\hline B8 & 9.7 & 7.4 & n.s & 6.1 & 7.9 & n.s \\
\hline \multirow[t]{2}{*}{ B35 } & 31.6 & 33.8 & n.s & 36.4 & 32.9 & n.s \\
\hline & $(\mathrm{N}=236)$ & $(\mathrm{N}=116)$ & & $(\mathrm{N}=33)$ & $(\mathrm{N}=83)$ & \\
\hline DR 1 & 17.3 & 18.9 & n.s & 15.1 & 20.4 & n.s \\
\hline DR2 & 41.1 & 40.5 & n.s & 24.2 & 46.9 & $<0.05$ \\
\hline DR3 & 24.1 & 17.2 & n.s & 15.1 & 18.0 & n.s \\
\hline DR5 & 36.4 & 62.9 & $<0.001$ & 69.7 & 60.2 & n.s \\
\hline
\end{tabular}

* Changes in the frequencies of these HLA antigens have been reported in HIV infection.

rapid progression, have not been detected with increased frequencies in our study.

An important marker of disease progression in AIDS is the decline of CD4+ T cell count. Studies in haemophiliacs and other risk groups have shown association of fast decline of CD4+ T cells with certain HLA phenotypes (Steel et al., 1988; Kaslow et al., 1990; Kaplan et al., 1990). Our findings are suggestive of an association of HLA-A9, -DR1 and -DR3 with declining numbers of CD4+ T cells during the follow up period, although this association was not statistically significant. However, similar associations have also been observed by others. Kaslow et al. (1990) have reported an increased frequency of HLA-A24 (A9) in rapid decliners compared to slow ones, whereas Steel et al. (1988) and Kaplan et al. (1990) have found associations with certain haplotypes that include HLA-B8 and -DR3.

It has been suggested that homozygosity might present a disadvantage in the response to the infectious agents. In a multicentre European study it has been observed that symptomatic HIV infected patients carried only one HLA antigen of a series more frequently than asymptomatic ones. This may be due to true homozygosity or to failure in detecting HLA antigens with the conventional serological techniques in this group of patients (Svejgaard, 1991). In our study, we did not observe any difference in the distribution of possibly homozygous individuals (with one HLA antigen of a series) between the two groups of asymptomatic (stage II+III) and symptomatic (stage IV) patients. These results may reflect a real situation as serotyping of our cohort of haemophiliacs was performed at an early asymptomatic stage of HIV infection, and for 
Table 2. Comparison of HLA antigen frequencies between HIV+ haemophiliacs in CDC stage II + III vs IV.

\begin{tabular}{|c|c|c|c|c|c|}
\hline & Controls & HIV- & $\mathrm{HIV}+$ & HIV+ & \\
\hline & & & $\begin{array}{l}\mathrm{CDC} \\
(\mathrm{II}+\mathrm{III})\end{array}$ & CDC (IV) & \\
\hline & $(\mathrm{N}=433)$ & $(\mathrm{N}=33)$ & $(\mathrm{N}=44)$ & $(\mathrm{N}=44)$ & \\
\hline HLA* & $\%$ & $\%$ & $\%$ & $\%$ & $\mathrm{P}$ \\
\hline $\mathrm{Al}$ & 24.0 & 18.2 & 22.7 & 27.2 & n.s \\
\hline A2 & 53.1 & 27.3 & 50.0 & 45.4 & n.s \\
\hline A9 & 33.0 & 51.5 & 15.9 & 43.1 & $<0.0$ \\
\hline B8 & 9.7 & 6.1 & 9.0 & 9.0 & n.s \\
\hline \multirow[t]{2}{*}{ B35 } & 31.6 & 36.4 & 29.5 & 36.3 & n.s \\
\hline & $(\mathrm{N}=236)$ & $(\mathrm{N}=33)$ & $(\mathrm{N}=39)$ & $(\mathrm{N}=44)$ & \\
\hline DRI & 17.3 & 15.1 & 17.9 & 22.7 & n.s \\
\hline DR2 & 41.1 & 24.2 & 51.2 & 43.2 & n.s \\
\hline DR3 & 24.1 & 15.1 & 10.2 & 25.0 & n.s \\
\hline DR5 & 36.4 & 69.7 & 53.8 & 65.9 & n.s \\
\hline
\end{tabular}

* Changes in the frequencies of these HLA antigens have been reported in HIV infection.

some of them even before HIV seroconversion, when probably there was no effect of HIV on the expression of HLA antigens.

In conclusion, our data revealed weak associations of HLA antigens with susceptibility to HIV infection and with disease progression. However a more detailed analysis of MHC alleles including the study of HLA class III alleles may prove more informative (Mallal et al., 1990; Cameron et al., 1991). In addition, studies of extended haplotypes may be of importance in revealing stronger associations with genes within the MHC area (Steel et al., 1988; Mallal et al., 1990; Kalow et al., 1990).

\section{ACKNOWLEDGEMENTS}

We thank Mrs Niki Kloni and Mrs Katerina Tsagraki for their technical assistance. This work was supported by funds from the Ministry of Health, Welfare and Social Security, E 134/20-12-1988. 
Table 3. Comparison of HLA antigen frequencies between HIV seropositive haemophiliacs with low or high CD4+ T cell counts.

\begin{tabular}{lcccc}
\hline & \multicolumn{4}{c}{ Haemophiliacs } \\
& Controls & $\mathrm{CD} 4+\geq 200$ & $\mathrm{CD} 4+<200$ & \\
\hline HLA* & $(\mathrm{N}=433)$ & $(\mathrm{N}=36)$ & $(\mathrm{N}=50)$ & \\
\hline A1 & 24.0 & 27.8 & 26.0 & $\mathrm{P} . \mathrm{s}$ \\
A2 & 53.1 & 55.5 & 42.0 & n.s \\
A9 & 33.0 & 19.4 & 36.0 & n.s \\
B8 & 9.7 & 13.8 & 4.0 & n.s \\
B35 & 31.6 & 30.5 & 34.0 & n.s \\
& & & & \\
& $(\mathrm{N}=236)$ & $(\mathrm{N}=33)$ & $(\mathrm{N}=39)$ & \\
\hline DR1 & 17.3 & 12.1 & 27.0 & n.s \\
DR2 & 41.1 & 57.6 & 39.6 & n.s \\
DR3 & 24.1 & 12.1 & 18.7 & n.s \\
DR5 & 36.4 & 63.6 & 60.4 & n.s \\
\hline
\end{tabular}

* Changes in the frequencies of these HLA antigens have been reported in HIV infection.

\section{REFERENCES}

Cameron, P.U., Mallal, S., French, M. and Dawkins R. (1991). Central MHC genes between HLA-B and complement C4 confer risk for HIV-1 disease progression. 11th International Histocompatability Workshop and Conference, Yokohama, Japan, abs. PS-19-2(MS-A6-10), 220.

Enlow, R.W., Nunez Roland, A., Lo Galbo, P., Mildvan, D., Mathur, U. and Winchester, R.J. (1983). Increased frequency of HLA-DR5 in lymphadenopathy stage of AIDS. Lancet, ii, 5152.

Fabio, G., Scorza Smeraldi, R., Gringeri, A., Marchini, M., Bonara, P.and Mannuci, P. (1990). Susceptibility to HIV infection and AIDS in Italian haemophiliacs is HLA associated. British Journal of Haematology, 75, 531-536.

Hershow, R., Targonski, P., Trowbridge, J., Gavanaugh, M., Graber, J. and Scott, H. (1991). HLA associations with HIV infection and progression in Chicago men. VII International Conference of AIDS, Florence, abs. MC 3153, 336.

Itestu, S., Brancato, L.J. and Winchester, R. (1989). A sicca syndrome in HIV infection association with HLA-DR5 and CD8 lymhocytosis. Lancet, 2, 446-8.

Jeannet, M., Sztajrel, R., Carpantier, N., Hirschel, B.and Tiercy, J.M. (1989). HLA antigens are risk factors for development of Aids. J. AIDS, 2, 28-32.

Kaplan, C., Muller, J., Doinel, C. (1990). HLA associated susceptibility to AIDS in HIV-1 seropositive subjects. Human Hered, 40, 290-298. 
Kaslow, R., Duquensoy, R., Van Raden, M., Kingsley, L., Marrari, M., Friedman, H., Su, S., Saah, A., Detels, R., Rhair, J.and Rinaldo, C. (1990). A1 CW7B8DR3 HLA antigen combination associated with rapid decline of T-helper lymphocytes in HIV-1 infection. Lancet, 335, 927 930.

Letenneur, L., Commenges, D., Pizet, D., Ladner, J., Dabis, F. and the Groupe d'Epidemiologie Clinique du Sida on Aquitaine (GESCA). (1991). Relationship between HLA phenotype and progression towards symptomatic HIV infection. VII International Conference on AIDS, Florence, abs. MC 3188, 345.

Mallal, S., Cameron, P.U., French, M.A.H., Dawkins, R.L. (1990). MHC genes and HIV infection. Lancet, i, 1591-92.

Mann, D., Carringhton, M., O’Donnel, M., O'Brien, S. and Goedert, J. (1991). HLA phenotype influences rate of progression and disease outcome in HIV-1 infection. VII International Conference on AIDS, Florence, abs. WA 1227, 148.

Mann, D.L., Murray, C., Yarchoan, R., Blattner, W.A. and Goedert J.J. (1988). HLA antigen frequencies in HIV-1 seropositive disease-free individuals and patients with AIDS. J AIDS, 1 , $13-17$.

Mengoli, C., Luzzati, R., Bassetti, D., Ciaffoni, S., Roata, O., Conte, R. and Raise, E. (1988). IV International AIDS Congress, Stockholm, abs. 2005, 165.

Moreno, M.E., Vilches, C., Pablo, R., Hernadez, C., Rementeria and Kreisler, M. (1991). Increase of HLA-DR6 in Spanish HIV infected individuals. IIth IHWC, Yokohama, Tokyo.

Papasteriades, Chr., Varla, M., Economidou, J., Markakis, K., Mitsouli, Chr., Louisou, K., Mandalaki, T., Roumeliotou, A. and Papaevangelou, G. (1986). High frequency of HLA-DR5 in Greek patients with haemophilia A and haemophilia B. Tissue Antigens, 28, 84-87.

Pollack, M.S., Safai, B. and Dupont, B. (1983). HLA-DR5 and DR2 are susceptibility factors for AIDS with Kaposi's sarcoma in different ethnic subpopulations. Disease Markers, 1, 135-9.

Raffoux, C., David, V., Couderc, L.D., Rabian, C., Clauvel, J.P., Seligmann, M. and Colombani, J. (1987). HLA-A, B and DR antigen frequencies in patients with AIDS-related persistent generalised lymphadenopathy (PGL) and thrombocytopenia. Tissue Antigens, 29, 60-62.

Scorza Smerdaldi, R., Fabio, G., Lazzarin, A., Eisera, N., Moroni, M. and Zanussi, C. (1986). HLA-associated susceptibility to AIDS in Italian patients with human immunodeficiency virus infection. Lancet, ii, 1187-89.

Steel, C.M., Ludlam, Ca., Beatson, D, et al. (1988). HLA haplotype A1B8DR3 as a risk factor for HIV-related disease. Lancet, i, 1185-8.

Svejaard, A. (1991). Personal Communication, Concerted Action on Immunogenetics of AIDS. Final Report.

Walker, B.D. and Plata, F. (1990). Cytotoxic T lymphocytes against HIV. AIDS, 4, 177-184. 


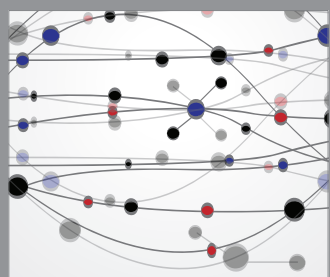

The Scientific World Journal
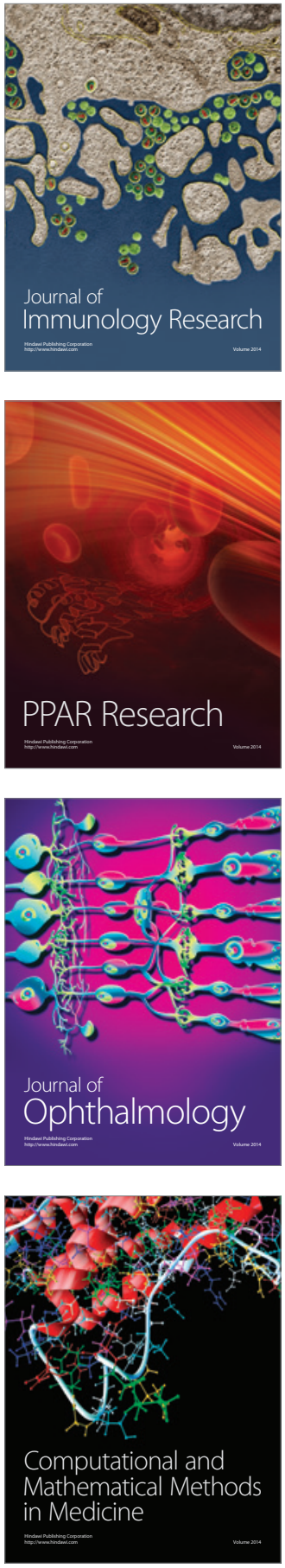

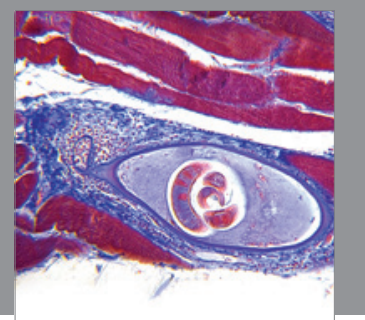

Gastroenterology

Research and Practice
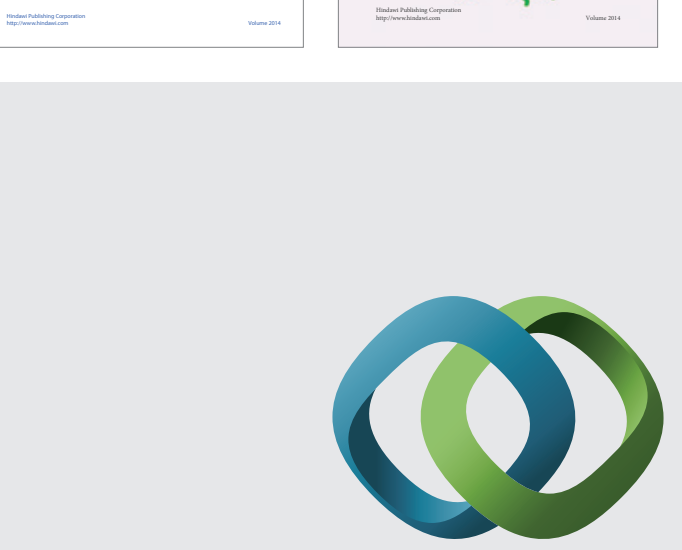

\section{Hindawi}

Submit your manuscripts at

http://www.hindawi.com
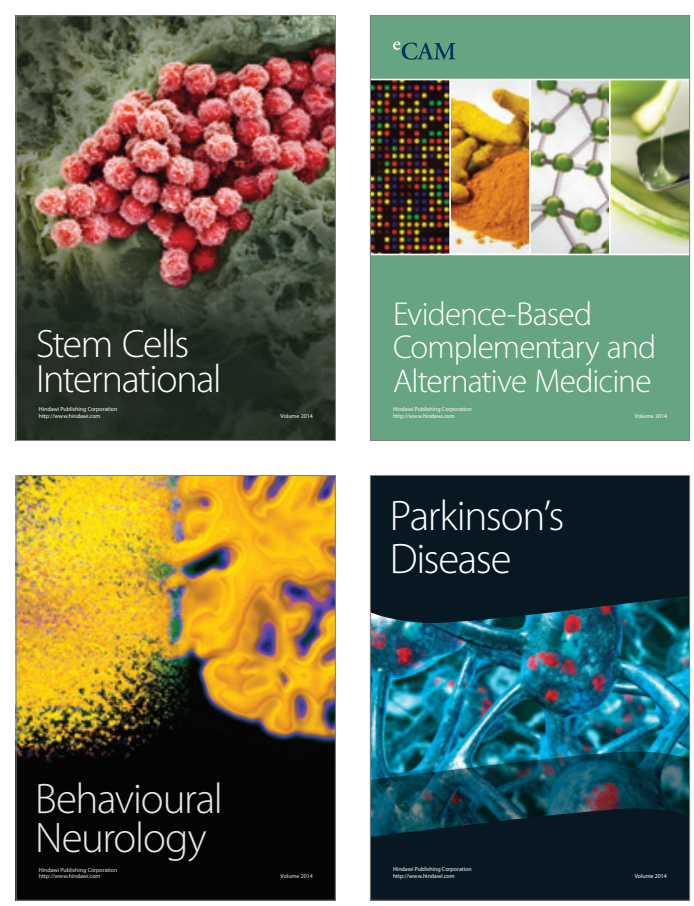

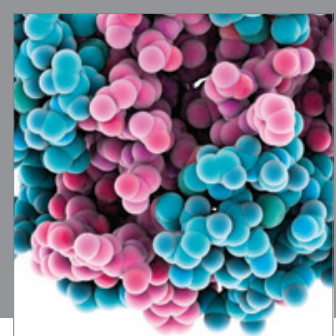

Journal of
Diabetes Research

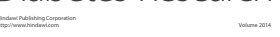

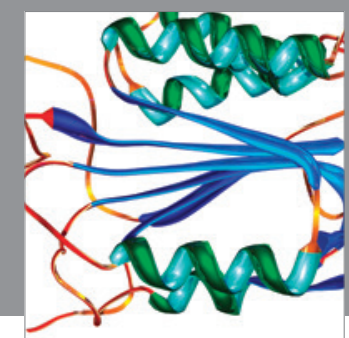

Disease Markers
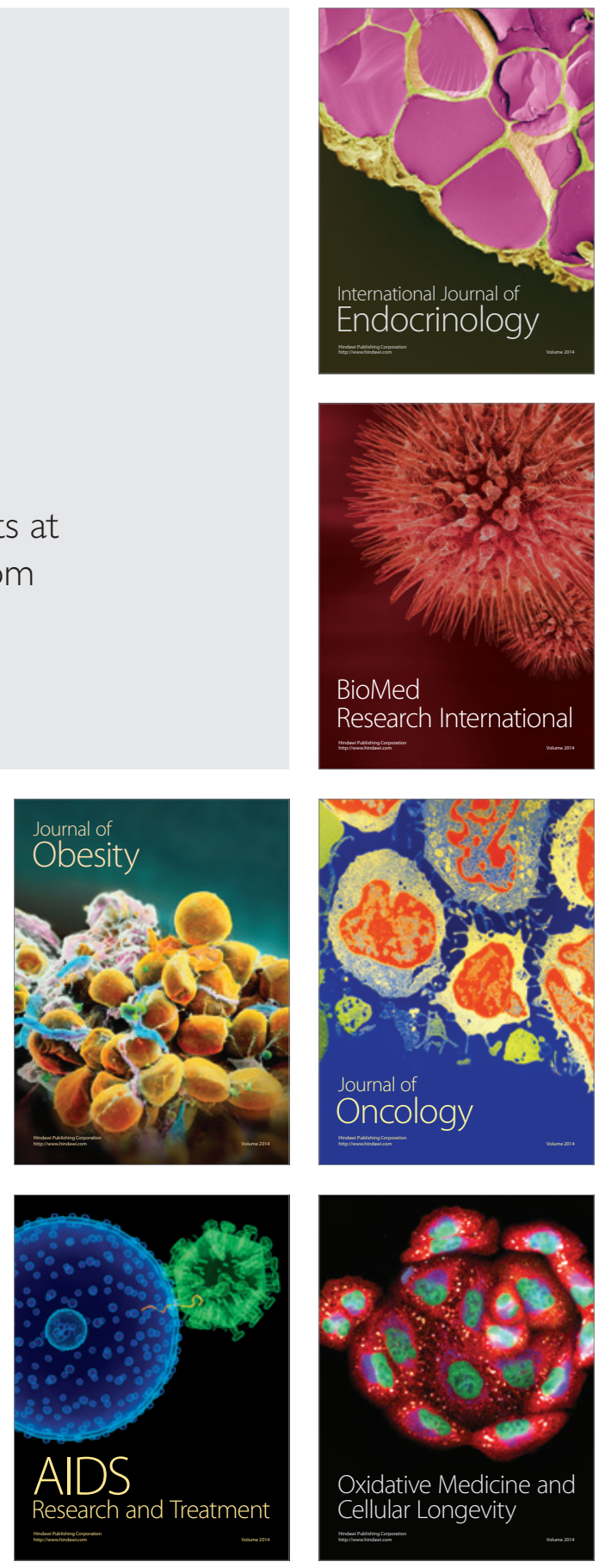